\title{
BIOATIVIDADE DO EXTRATO AQUOSO DE SEMENTES DE NIM SOBRE Tuta absoluta (MEYRICK, 1917) (LEPIDOPTERA: GELECHIIDAE) EM TRÊS FORMAS DE APLICAÇÃ̃O
}

\author{
Bioactivity of aqueous neem seeds extract on the Tuta absoluta (Meyrick, 1917) \\ (Lepidoptera: Gelechiidae) in three ways of application
}

Rita de Cássia Rodrigues Gonçalves-Gervásio², José Djair Vendramim³

\begin{abstract}
RESUMO
No presente trabalho, avaliaram-se as atividades translaminar, sistêmica e de contato do extrato aquoso de sementes de Azadirachta indica A. Juss. (nim) sobre a traça-do-tomateiro Tuta absoluta (Meyrick). Foram realizados três experimentos envolvendo extratos aquosos de sementes de nim em concentrações de 0,$5 ; 1,0 ; 5,0$ e 10,0 g por $100 \mathrm{~mL}$ de água. Esses extratos foram aplicados no solo, na superfície adaxial de folíolos de tomateiro e diretamente sobre as lagartas. Quando os extratos foram aplicados no solo, em vasos contendo plantas de tomate, houve mortalidade de 48,3 a 100,0\% das lagartas, indicando que foram absorvidos e translocados na planta. Também ocorreu mortalidade larval de 57,0 a 100,0\% quando os extratos foram aplicados na superfície adaxial do folíolo, evidenciando o efeito translaminar. Quando foi aplicado diretamente sobre lagartas com seis dias de idade, observou-se mortalidade de 52,4 a $95,4 \%$, demonstrando a ação de contato do composto e seu potencial para controle da traça-do-tomateiro.
\end{abstract}

Termos para indexação: Planta inseticida, Azadirachta indica, traça-do-tomateiro.

\begin{abstract}
This work, aimed to study the translaminar, systemic and contact action of aqueous neem seeds extracts on the tomato leafminer Tuta absoluta (Meyrick). Three experiments with aqueous neem seeds extracts at concentrations of $0.5 ; 1.0 ; 5.0$ and $10.0 \mathrm{~g} /$ $100 \mathrm{~mL}$ of water were conducted. These extracts were applied in the soil, in adaxial surface of the tomato plant foliole and directly over the insect. When the extracts were applied in the soil of pots containing tomato plants, the larval mortality rate was $48.3 \%$ to $100.0 \%$, indicating that the extracts were absorbed and transferred inside the plant. There was also a larval mortality of $57.0 \%$ to $100.0 \%$ when the extracts were applied over the foliole adaxial surface, which shows the translaminar action. When the extracts were applied directly over larvae six days old, the larval mortality rate was $52.4 \%$ to $95.4 \%$, which shows the action of contact of the extracts and its potential to control the tomato leafminer.
\end{abstract}

Index terms: Insecticide plant, Azadirachta indica, tomato leafminer.

(Recebido para publicação em 22 de junho de 2005 e aprovado em 5 de julho de 2006)

\section{INTRODUÇÃO}

A traça-do-tomateiro Tuta absoluta (Meyrick, 1917) (Lepidoptera: Gelechiidae) é uma praga de grande importância econômica nessa cultura. Os danos decorrentes do seu ataque podem ser observados na parte aérea da planta, sendo que as lagartas constroem minas nas folhas, ramos e frutos, as quais aumentam à medida que o inseto se alimenta. Sob ataque intenso as folhas amarelecem, murcham e caem, os frutos são destruídos, podendo inclusive ocorrer morte da planta (MALUF et al., 1997; SCARDINI et al., 1983; SOUZA et al., 1983).

Entre as medidas de controle usadas pelos agricultores, o método químico tem sido o mais utilizado. Contudo, os efeitos adversos do uso indiscriminado de inseticidas têm provocado o aparecimento de biótipos resistentes, fazendo com que o agricultor utilize dosagens cada vez maiores sem obter resultado satisfatório (SIQUEIRA et al., 2000).

Acredita-se que o emprego de métodos alternativos de controle, dentre os quais o uso de plantas inseticidas poderá ser uma ferramenta importante no manejo integrado de pragas. De acordo com Roel (2001), o emprego de substâncias extraídas de plantas no controle de pragas, apresenta algumas vantagens, quando comparado ao uso de produtos sintéticos. Os inseticidas naturais não deixam resíduos, apresentam menor custo de produção e são rapidamente degradáveis. Dentre as plantas cujo extrato tem poder inseticida, o nim, Azadirachta indica A. Juss. (Meliaceae) é uma espécie que tem sido estudada e destaca-se pela sua eficiência no controle de artrópodespraga e baixa toxicidade aos inimigos naturais e ao homem (MARTINEZ, 2002).

${ }^{1}$ Parte da tese de doutorado do primeiro autor apresentada à Escola Superior de Agricultura Luiz de Queiroz (ESALQ/USP).

${ }^{2}$ Professora Adjunto, Colegiado de Engenharia Agrícola e Ambiental/UNIVASF - 48.900-000 - Juazeiro,BA - rita.gervasio@univasf.edu.br

${ }_{3}$ Professor Titular, Departamento de Entomologia, Fitopatologia e Zoologia Agrícola da ESALQ/USP - 13418-900 - Piracicaba, SP - jdvendra@esalq.usp.br 
O efeito inseticida dessa espécie vegetal sobre $T$. absoluta foi demonstrado por Trindade et al. (2000). Lagartas recém-eclodidas foram confinadas em tubos contendo um folíolo de tomateiro, previamente imerso em extrato metanólico de sementes de nim nas concentrações de 2000; 4000; 6000 e 8000 mg/L. Aos quatro dias foi observada mortalidade acima de $80 \%$, sendo que ao sexto dia todas as concentrações haviam causado $100 \%$ de mortalidade larval. Entretanto, não se sabe o modo de ação quando o mesmo é aplicado topicamente sobre lagartas de T. absoluta, no solo ou sobre folíolos de tomateiro já infestados pela praga. Assim, no presente trabalho, avaliouse a atividade do extrato aquoso de sementes de nim aplicado sobre lagartas de T. absoluta, em folíolos infestados e no solo de vasos contendo tomateiro.

\section{MATERIAL E MÉTODOS}

Os experimentos foram realizados, em casa-devegetação e em laboratório, empregando extrato aquoso de sementes de $A$. indica (nim) em concentrações 0,$5 ; 1,0 ; 5,0$ e $10,0 \mathrm{~g}$ por $100 \mathrm{~mL}$ de água destilada. As concentrações utilizadas nos diferentes testes foram definidas em ensaios preliminares. Os extratos foram preparados seguindo metodologia utilizada por Rodríguez \& Vendramim (1996). As misturas do pó de sementes de nim com água destilada foram mantidas em aparelho de ultra-som por 40 minutos para extração dos compostos hidrossolúveis. Após esse processo, as misturas foram filtradas, obtendo-se os extratos nas concentrações desejadas para realização dos testes.

Para verificar a ação translaminar, foi realizado um teste em casa-de-vegetação (Temp.: 21,9 $\pm 10,9^{\circ} \mathrm{C}$; UR: 71,4 $\pm 33,9 \%$; fotoperíodo natural), usando os extratos nas concentrações de 0,$5 ; 1,0$ e $5,0 \%$ e uma testemunha representada por água destilada. Foram utilizados tomateiros, Cultivar Santa Clara, com aproximadamente 25 dias de idade, sendo que em cada planta, foram marcados quatro folíolos do terço médio, os quais receberam três lagartas recém-eclodidas da traça-do-tomateiro, provenientes de uma criação mantida em laboratório. Após a penetração das lagartas nas minas, os extratos foram pincelados na superfície adaxial dos folíolos. Após a evaporação do excesso de umidade, cada folíolo foi protegido por uma gaiola confeccionada com uma placa de acrílico de $6 \mathrm{~cm}$ de diâmetro e $2 \mathrm{~cm}$ de altura, a qual teve o fundo removido e substituído por um tecido fino (voil) para promover melhor aeração no seu interior. Essa gaiola foi utilizada com o objetivo de evitar a fuga das lagartas e permitir o acompanhamento do seu desenvolvimento. Considerando os resultados obtidos por Schmutterer (1990) e Stokes \& Redfern (1982), os quais verificaram que extratos de nim aplicados sobre plantas podem permanecer ativos por cerca de uma semana, a aplicação do extrato aquoso de nim foi repetida após sete e 14 dias, sendo essa última realizada apenas nos folíolos em que o inseto ainda se encontrava na fase larval. Após sete dias da infestação, foi feita uma avaliação do desenvolvimento das minas causadas pelas lagartas nos folíolos. Seguindo metodologia proposta por Picanço et al. (1995), as minas foram classificadas em pequenas (menos que $0,5 \mathrm{~cm}$ de comprimento), médias ( 0,5 a $1,0 \mathrm{~cm}$ de comprimento) e grandes (mais de 1,0 cm de comprimento). Quando os folíolos infestados estavam totalmente danificados, as lagartas eram transferidas para novos folíolos e após a penetração das mesmas no mesofilo foliar, o tratamento era novamente aplicado. O número de pupas obtidas em cada tratamento foi registrado e, a partir desse dado, foi calculada a viabilidade larval. $\mathrm{O}$ experimento seguiu o delineamento inteiramente casualizado com quatro tratamentos (três concentrações do extrato e testemunha) e cinco repetições, sendo que cada repetição foi representada por uma planta com 12 lagartas.

A ação sistêmica foi verificada por meio de um teste conduzido em casa-de-vegetação (Temp.: $30,3 \pm 12,5^{\circ} \mathrm{C}$; UR: $64,1 \pm 34,2 \%$; fotoperíodo natural), utilizando-se mudas de tomateiro (Cultivar Santa Clara) em vasos com capacidade de aproximadamente $3 \mathrm{~L}$. Após 20 dias do transplante, cada vaso recebeu $100 \mathrm{~mL}$ de extrato, nas concentrações de 0,5 ; 1,0; 5,0 e 10,0\%, além de uma testemunha só com água. O experimento seguiu o delineamento inteiramente casualizado com cinco tratamentos (quatro concentrações do extrato e testemunha) e cinco repetições, sendo cada repetição representada por uma planta com 12 lagartas. Após 24 h da aplicação dos tratamentos, quatro folíolos do terço médio de cada planta, foram infestados com três lagartas de $T$. absoluta recém-eclodidas e protegidos com uma gaiola semelhante àquela utilizada no teste anterior. No decorrer do experimento, as irrigações foram feitas, colocando-se a mesma quantidade de água por vaso, evitando o excesso de forma que os extratos não se perdessem por lixiviação. A aplicação dos extratos foi repetida após sete e 14 dias, sendo que aos sete dias foi feita avaliação do desenvolvimento das minas.

A ação tópica foi determinada em laboratório (T: $25 \pm 2,0^{\circ} \mathrm{C}$; UR: $70 \pm 10,0 \%$; fotofase de $12 \mathrm{~h}$ ). Nesse teste, foram feitas aplicações tópicas dos extratos em lagartas de segundo estádio (seis dias de idade), utilizando-se uma microsseringa. Foi aplicado 0,1 microlitrode extrato no dorso de cada lagarta, sendo utilizadas 75 lagartas por tratamento. 
No tratamento testemunha, essas receberam 0,1 microlitrode água destilada. Os insetos foram mantidos em tubos de vidro de $2,5 \mathrm{~cm}$ de diâmetro e $8,5 \mathrm{~cm}$ de altura, contendo um folíolo de tomateiro com o pecíolo envolvido em algodão umedecido. $\mathrm{O}$ delineamento foi o inteiramente casualizado com quatro tratamentos nas concentrações de 1,0; 5,0;10,0\% e testemunha com cinco repetições, cada uma constituída por cinco tubos com três lagartas, totalizando 15 lagartas por repetição. Foram feitas avaliações diárias da mortalidade até que as lagartas atingissem o estágio de pupa.

Em todos os testes, os dados de mortalidade foram submetidos à análise de variância pelo teste $\mathrm{F}$, sendo as médias comparadas pelo teste de Tukey $(\mathrm{P} \leq 0,05)$. Nas situações em que ocorreram valores extremos de mortalidade, o teste de Tukey foi aplicado, utilizando-se o valor teórico da variância residual (HADDAD \& VENDRAMIM, 2000). A partir dos dados de mortalidade, calculou-se a porcentagem de eficiência do extrato de nim, corrigindo-se a mortalidade pela fórmula de Abbott (1925).

\section{RESULTADOS E DISCUSSÃO}

$\mathrm{O}$ extrato aquoso de sementes de nim a $5 \%$ aplicado na superfície adaxial dos folíolos de tomateiro provocou mortalidade de $100 \%$ de lagartas de T. absoluta, não diferindo do tratamento que empregou o extrato a $1 \%$. O extrato na concentração de $0,5 \%$ provocou $57,0 \%$ de mortalidade, diferindo dos resultados observados nas demais concentrações (Tabela 1).

Existem poucas informações sobre a ação translaminar de compostos presentes em extratos de nim. Esse efeito foi demonstrado por Verkerk et al. (1998) ao estudarem a ação inseticida de extratos de sementes dessa planta para os pulgões Myzus persicae (Sulzer, 1776) e Brevicoryne brassicae (Linnaeus, 1758) (Hemiptera: Aphididae). Os tratamentos foram aplicados na superfície adaxial de folhas de repolho, enquanto ninfas desses afídeos foram confinadas em gaiolas fixadas na superfície abaxial das mesmas. Registrouse $100 \%$ de mortalidade das ninfas após $96 \mathrm{~h}$ da aplicação dos extratos, enquanto no tratamento-controle, folhas tratadas com água destilada, não foram observados insetos mortos.

Os resultados demonstraram que o efeito translaminar foi evidente, uma vez que mesmo nas menores concentrações, o extrato provocou valores significativos de mortalidade larval. Provavelmente, esse extrato contém substâncias ativas capazes de penetrar a epiderme foliar do tomateiro, atingindo as larvas que se alimentam no mesofilo, condição considerada essencial no controle de insetos minadores (STEIN \& PARRELLA, 1985; WEBB et al., 1983).

$\mathrm{Na}$ avaliação do desenvolvimento das minas nas folhas, aos sete dias, foi possível observar diferenças entre os tratamentos aplicados na superfície das folhas. Plantas que receberam extratos nas concentrações de 1,0 e 5,0\% apresentaram grande porcentagem de minas pequenas, sendo que nenhuma mina grande foi verificada no tratamento com extrato a 5\%. No tratamento correspondente à aplicação do extrato na menor concentração $(0,5 \%)$, a maioria das minas encontradas foi classificada como média ou pequena, constatando-se cerca de $30 \%$ de minas grandes. No tratamento-testemunha, por sua vez, todas as folhas infestadas apresentaram minas grandes (Figura 1).

TABELA 1 - Mortalidade (\%) ( \pm EP) de lagartas de Tuta absoluta exposta ao extrato aquoso de sementes de nim sob diferentes formas de aplicação. Piracicaba, SP.

\begin{tabular}{cccccccc}
\hline \multirow{2}{*}{$\begin{array}{c}\text { Extratos de } \\
\text { nim (\%) }\end{array}$} & \multicolumn{2}{c}{ Folíolo $^{\mathbf{1}}$} & \multicolumn{2}{c}{ Solo } & \multicolumn{2}{c}{ Tópica $^{\mathbf{2}}$} \\
\cline { 2 - 7 } & Mortalidade $^{\mathbf{3 , 4}}$ & Eficiência $^{\mathbf{5}}$ & Mortalidade $^{\mathbf{3 , 4}}$ & Eficiência $^{\mathbf{5}}$ & Mortalidade $^{\mathbf{4}}$ & Eficiência $^{\mathbf{5}}$ \\
\hline 10,0 & - & - & $100,0 \pm 0,00 \mathrm{a}$ & 100,0 & $95,4 \pm 1,90$ & $\mathrm{a}$ & 95,3 \\
5,0 & $100,0 \pm 0,00 \mathrm{a}$ & 100 & $98,3 \pm 1,67 \mathrm{a}$ & 98,2 & $75,2 \pm 10,05$ ab & 74,5 \\
1,0 & $96,8 \pm 2,04 \mathrm{a}$ & 96,6 & $81,7 \pm 4,86 \mathrm{~b}$ & 80,4 & $52,4 \pm 4,84 \mathrm{~b}$ & 51,0 \\
0,5 & $57,0 \pm 6,33 \mathrm{~b}$ & 54,2 & $48,3 \pm 3,12 \mathrm{c}$ & 44,6 & - & - & - \\
\hline
\end{tabular}

${ }^{1}$ Mortalidade não avaliada para a concentração de $10 \%$.

${ }^{2}$ Mortalidade não avaliada para a concentração de $0,5 \%$.

${ }^{3}$ Para efeito de análise estatística, os dados foram transformados em $\operatorname{arc} \operatorname{sen} \sqrt{\mathrm{x} / \mathrm{N}}$.

${ }^{4}$ Médias seguidas de mesma letra, nas colunas, não diferem entre si, pelo teste de Tukey (Pd”0,05).

${ }^{5}$ Porcentagem de mortalidade corrigida pela fórmula de Abbott (1925). 
Sabe-se que as lagartas de T. absoluta não permanecem no interior das minas durante todo o período de desenvolvimento, dificultando a avaliação do efeito translaminar do extrato. Entretanto, a avaliação do tamanho das minas sugere a ocorrência desse efeito, uma vez que a mesma foi realizada quando as lagartas estavam com sete dias de idade. De acordo com Marques \& Alves (1996), nesse período a movimentação das lagartas entre os folíolos é pequena, o que dificultaria o seu contato direto com o produto. Dessa forma, compostos responsáveis pela redução da alimentação, provavelmente atravessaram a epiderme, atingindo a lagarta no mesofilo.

Quando o extrato de sementes de nim foi aplicado no solo, observaram-se nas concentrações de 10 e 5\% índices de mortalidade superiores a $98 \%$, sendo que esses tratamentos não diferiram entre si. Os tratamentos correspondentes às concentrações de 0,5 e $1,0 \%$ provocaram 48,3 e $81,7 \%$ de mortalidade, respectivamente. Esses resultados diferiram entre si, e foram superiores àquele observado na testemunha $(6,7 \%)$ (Tabela 1$)$.

Nesse teste, verificou-se que compostos inseticidas presentes nos extratos são capazes de atingir o inseto na parte aérea da planta, mesmo quando aplicados no solo. Esse efeito, já demonstrado por diversos autores em relação a outras espécies de insetos, é bastante desejável para produtos à base de nim, uma vez que os compostos ativos encontrados nos extratos dessa planta são altamente sensíveis à radiação (OSMAN \& PORT, 1990; SCHMUTTERER, 1990).

O efeito sistêmico de compostos presentes em produtos à base de nim é bem documentado na literatura
(HOLMES \& HASSAN, 1999; LAREW et al., 1985; SHIVASHANKAR et al., 2000; SUNDARAM et al., 1995). Um aspecto relevante é que o extrato aquoso de sementes dessa espécie vegetal tem efeito inseticida sistêmico mesmo para lagartas, as quais apresentam aparelho bucal mastigador. Assim, Osman \& Port (1990) demonstraram que o extrato aquoso e o pó de sementes de nim aplicados diretamente no solo provocaram redução significativa nos danos devido à morte de lagartas de quinto ínstar de Pieris brassicae (Linnaeus, 1758) (Lepidoptera: Pieridae) em plantas de repolho.

Rovesti \& Deseö (1991) testaram a atividade sistêmica de extrato aquoso de sementes de nim sobre lagartas do minador Leucoptera malifoliella (Costa, 1836) (Lepidoptera: Lyonetiidae) em folhas de macieira na Itália. A aplicação do extrato no solo e nas folhas mais baixas da planta permitiu que o composto fosse absorvido e translocado para a parte aérea, reduzindo significativamente o número de pupas nas plantas tratadas, sendo que o efeito mais drástico dos tratamentos foi verificado em folhas do terço inferior das plantas.

Quanto ao desenvolvimento das minas aos sete dias após o tratamento, quando o extrato foi aplicado no solo, verificou-se, nas concentrações de 5 e $10 \%$, predominância de minas pequenas e médias em todos os folíolos das plantas tratadas. No tratamento a $1 \%$, houve predominância de minas de tamanho médio, enquanto que a $0,5 \%$ predominaram as minas médias e grandes em proporções semelhantes e na testemunha, $86,21 \%$ das minas foram classificadas como grandes (Figura 2).

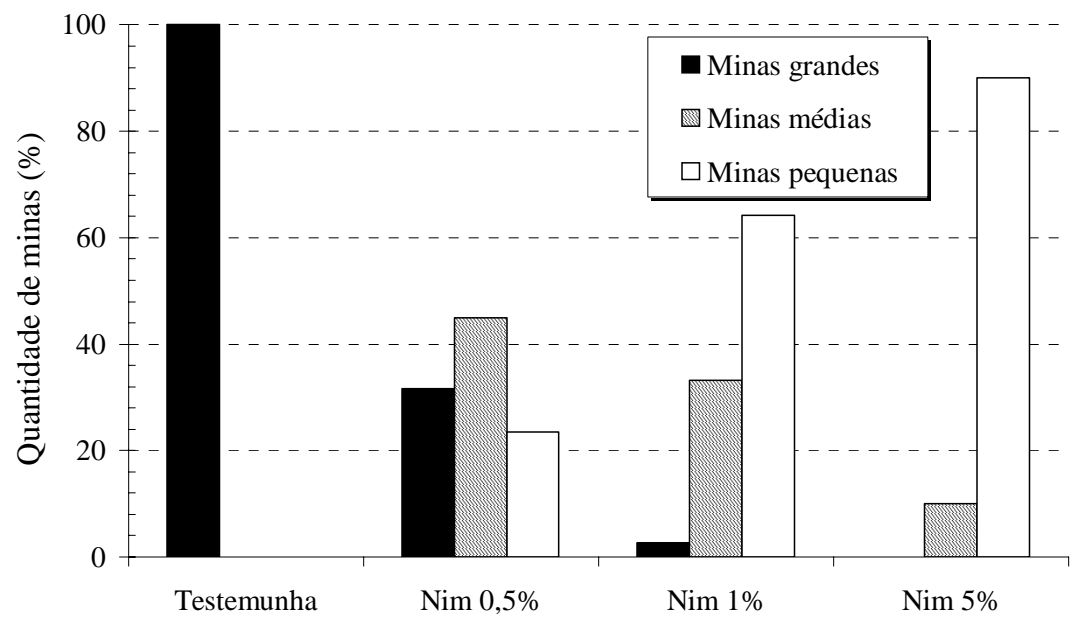

FIGURA 1 - Porcentagem de minas grandes (mais de $1,0 \mathrm{~cm}$ de comprimento), médias ( 0,5 a 1,0 cm de comprimento) e pequenas (menos de $0,5 \mathrm{~cm}$ de comprimento) provocadas por lagartas de Tuta absoluta em folíolos de tomateiro com a superfície adaxial tratada com extratos aquosos de sementes de nim, após sete dias da aplicação. Temp.: 21,9 10,9 ${ }^{\circ} \mathrm{C}$; UR: 71,4 33,9\%; fotoperíodo natural. Piracicaba, SP. 


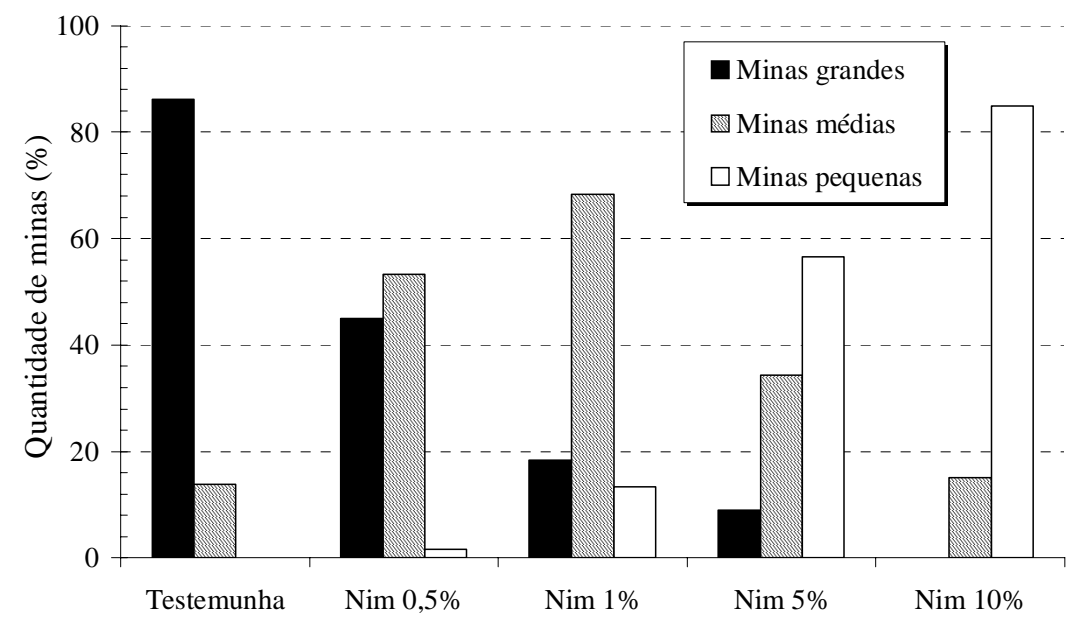

FIGURA 2 - Porcentagem de minas grandes (mais de $1,0 \mathrm{~cm}$ de comprimento), médias ( 0,5 a 1,0 cm de comprimento) e pequenas (menos de $0,5 \mathrm{~cm}$ de comprimento) provocadas por lagartas de Tuta absoluta em folíolos de plantas de tomateiro cultivadas em solo tratado com extratos aquosos de sementes de nim. Temp.: $30,3 \pm 12,5^{\circ} \mathrm{C}$; UR: $64,1 \pm 34,2 \%$; fotoperíodo natural. Piracicaba, SP.

Quando o extrato de nim foi aplicado topicamente, a mortalidade das lagartas de segundo ínstar de T. absoluta foi maior do que aquela observada na testemunha. O efeito mais acentuado foi verificado quando se utilizou o extrato na concentração de $10,0 \%$, no qual a mortalidade a $95 \%$ (Tabela 1).

O efeito de extratos de nim, por meio da aplicação tópica, também foi demonstrado para outras espécies de insetos. Abraham \& Ambika (1979) verificaram que extratos acetônicos de folhas e sementes dessa meliácea, aplicados sobre o abdomêm de ninfas de terceiro, quarto e quinto estádios de Dysdercus cingulatus (Fabricius, 1775) (Hemiptera: Pyrrhocoridae) afetaram de forma negativa o desenvolvimento e reprodução desse percevejo. De forma semelhante, Tanzubil \& McCaffery (1990) relataram que quando lagartas do noctuídeo Spodoptera exempta (Walker, 1856) foram tratadas por imersão em extrato aquoso de sementes de nim a 5,0 e 10,0\% não se alimentaram e quando se utilizou a concentração de $10,0 \%$, ocorreu uma mortalidade de $100 \%$ após cinco dias da aplicação.

$\mathrm{Na}$ avaliação do efeito tópico, observou-se a necessidade de concentrações mais altas do extrato para obtenção de valores de mortalidade comparáveis aos observados nos outros testes. Isso pode ser um indicativo de que os compostos com efeito inseticida presentes no extrato de sementes de nim sejam mais eficientes quando ingeridos pelo inseto. A superioridade da ação de ingestão da azadiractina (principal composto inseticida em extratos de nim) foi constatada para o noctuídeo Spodoptera littoralis (Boisduval, 1833) ao se verificar que $\mathrm{a}_{50}$ obtida por ingestão de dieta durante dois dias mostrou-se cerca de 200 vezes inferior à obtida por pulverização (MARTINEZ, 2002).

Durante as avaliações, os sintomas observados nas lagartas foram semelhantes em todos os testes. Esses sintomas envolveram redução na alimentação, atraso no desenvolvimento e morte do inseto durante a troca de tegumento, o que caracteriza os efeitos fagodeterrente e regulador de crescimento atribuídos a extratos de $A$. indica como relatado por Govindachari et al. (2000), Mordue-Luntz \& Blackwell (1993), Mordue-Luntz et al. (1998) e Schumutterer (1990).

\section{CONCLUSÕES}

Nas condições que os experimentos foram conduzidos, foi possível concluir que:

- Compostos inseticidas presentes no extrato aquoso de sementes de nim são capazes de penetrar a epiderme foliar de tomateiro, atingindo lagartas de $T$. absoluta que se alimentam no mesofilo.

- Compostos inseticidas presentes no extrato aquoso de sementes de nim atuam sobre lagartas de $T$. absoluta na parte aérea da planta, mesmo quando esse é aplicado no solo.

- Quando aplicado de maneira tópica sobre lagartas de T. absoluta, o extrato de sementes de nim também provoca mortalidade significativa dos insetos. 


\section{AGRADECIMENTOS}

À Fapesp, pelo apoio financeiro para a realização dessa pesquisa.

\section{REFERÊNCIAS BIBLIOGRÁFICAS}

ABBOTT, W. S. A method of computing the effectiveness of an insecticide. Journal of Economic Entomology, College Park, v. 18, n. 1, p. 265-267, Feb. 1925.

ABRAHAM, C. C.; AMBIKA, B. Effect of leaf and kernel extracts of neem on moulting and vitellogenesis in Dysdercus cingulatus Fabr. (Heteroptera: Pyrrhocoridae). Current Science, Bangalore, v. 48, n. 12, p. 554-556, Jun. 1979.

GOVINDACHARI, T. R.; SURESH, G.; GOPALAKRISHNAN, G.; WESLEY, S. D. Insect antifeedant and growth regulating activities of neem seed oil: the role of major tetranortriterpenoids. Journal of Applied Entomology, Berlin, v. 124, n. 7/8, p. 287-291, Oct. 2000.

HADDAD, M. L.; VENDRAMIM, J. D. Comparação de porcentagens observadas com casos extremos de 0 e $100 \%$. Anais da Sociedade Entomológica do Brasil, Londrina, v. 29, n. 4, p. 835-837, dez. 2000.

HOLMES, M.; HASSAN, E. The contact and systemic action of neem seed extract against green peach aphid Myzus persicae Sulzer (Hemiptera: Aphididae). Azadirachta indica A. Jus, [S.1.], p. 93-101, 1999.

LAREW, H. G.; KNODEL-MONTZ, J. J.; WEBB, R. E.; WARTHEN, J. D. Liriomyza trifolii (Burguess) (Diptera: Agromyzidae) control on chrysanthemum by neem seed extract applied to soil. Journal of Economic Entomology, College Park, v. 78, n. 1, p. 81-84, Feb. 1985.

MALUF, W. R.; BARBOSA, L. V.; SANTA-CECÍLIA, L. V. C. 2-Tridecanone-mediated mechanism of resistance to the South American tomato pinworm Scrobipalpuloides absoluta (Meyrick, 1917) (Lepidoptera: Gelechiidae) in Lycopersicon spp. Euphytica, Dordrecht, v. 93, n. 2, p. 189194, 1997.

MARQUES, I. M. A.; ALVES, S. B. Efeito de Bacillus thuringiensis Berl. var. kurstaki sobre Scrobipalpuloides absoluta Meyer. (Lepidoptera: Gelechiidae). Anais da Sociedade Entomológica do Brasil, Londrina, v. 25, n. 1, p. 39-45, abr. 1996.
MARTINEZ, S. S. (Ed.). O nim Azadirachta indica: natureza, usos múltiplos, produção. Londrina: Instituto Agronômico do Paraná, 2002. 142 p.

MORDUE-LUNTZ, A. J.; BLACKWELL, A. Azadirachtin: an update. Journal of Insect Physiology, Oxford, v. 39, n. 11, p. 903-924, 1993.

MORDUE-LUNTZ, A. J.; SIMONDS, M. S. J.; LEY, S. V.; BLANEY, W. M.; MORDUE, W.; NASIRUDDIN, M.; NISBET, A. J. Action of azadirachtin, a plant allelochemical, against insects. Pesticide Science, Oxford, v. 54, p. 277-284, 1998.

OSMAN, M. Z.; PORT, G. R. Systemic action of neem seed substances against Pieris brassicae. Entomologia Experimentalis et Applicata, Amsterdam, v. 54, p. 297 300, 1990

PICANÇO, M. C.; SILVA, D. J. H. da; LEITE, G. L. D.; MATA, A. C. da; JHAM, B. N. Intensidade de ataque de Scrobipalpula absoluta (Meyrick, 1917) (Lepidoptera: Gelechiidae) ao dossel de três espécies de tomateiro. Pesquisa Agropecuária Brasileira, Brasília, v. 30, n. 4, p. 429-433, abr. 1995

RODRÍGUEZ, H. C.; VENDRAMIM, J. D. Toxicidad de extractos acuosos de Meliaceae en Spodoptera frugiperda (Lepidoptera: Noctuidae). Manejo Integrado de Plagas, Turrialba, v. 42, p. 14-22, 1996.

ROEL, R. A. Utilização de plantas com propriedades inseticidas: uma contribuição para o desenvolvimento rural sustentável. Revista Internacional de Desenvolvimento Local, [S.1.], v. 1, n. 2, p. 43-50, mar. 2001.

ROVESTI, L.; DESEÖ, K. V. Effectiveness of neem seed kernel extract against Leucoptera malifoliella Costa (Lep., Lyonetiidae). Journal of Applied Entomology, Berlin, v. 111, p. 231-236, 1991.

SCARDINI, D. M. B.; FERREIRA, L. R.; GALVEAS, P. A. O. Ocorrência da traça-do-tomateiro Scrobipalpuloides absoluta (Meyr.) no Estado do Espírito Santo. In: CONGRESSO BRASILEIRO DE ENTOMOLOGIA, 8., 1983, Brasília, DF. Resumos... Brasília, DF: SEB, 1983.p. 72.

SCHMUTTERER, H. Properties and potential of natural pesticides from the neem tree, Azadirachta indica. Annual Review of Entomology, Palo Alto, v. 35, p. 271-297, 1990. 
SHIVASHANKAR, T.; ANNADURAI, R. S.; SRINIVAS, M.; PREETHI, G.; SHARADA, T. B.; PARAMASHIVAPPA, R.; SRINIVASA-RAO, A.; PRABHU, K. S.; RAMADOSS, C. S.; VEERESH, G. K.; SUBBA-RAO, P. V. Control of coconut black-head caterpillar (Opsina arenosella Walker) by systemic application of 'Soluneem': a new water-soluble neem insecticide formulation. Current Science, Bangalore, v. 78, n. 2, p. 176-179, Jan. 2000.

SIQUEIRA, H. A. A.; GUEDES, R. N. C.; PICANÇO, M. C. Cartap resistance and sinergism in populations of Tuta absoluta (Lepidoptera: Gelechiidae). Journal of Applied Entomology, Berlin, v. 124, n. 5/6, p. 1-7, Sept. 2000.

SOUZA, J. C. de; REIS, P. R.; GOMES, J. M.; NACIF, A. P.; SALGADO, L. O. Traça-do-tomateiro: histórico, reconhecimento, biologia, prejuízos e controle. Belo Horizonte: Epamig, 1983. 15 p. (Boletim técnico, 2).

STEIN, U.; PARRELLA, M. P. Seed extract shows promise in leafminer control. California Agriculture, California, v. 4, p. 19-20. July/Aug. 1985.

STOKES, J. B.; REDFERN, R. E. Effect of sunlight on azadirachtin: antifeeding potency. Journal of Environmental Scientific Health, [S.1.], v. 17, p. 57-65, 1982.

SUNDARAM, K. M. S.; CAMPBELL, R.; SLOANE, L.; STUDENS, J. Uptake, translocation, persistence and fate of azadirachtin in aspen plants (Populus tremuloides Michx.) and effects on pestiferous two-spotted spider mite (Tetranychus urticae Koch). Crop Protection, Guilford, v. 14, n. 5, p. 415-421, Aug. 1995.

TANZUBIL, P. B.; McCAFFERY, A. R. Effects of azadirachtin and aqueous neem seed extracts on survival, growth and development of the African armyworm, Spodoptera exempta. Crop Protection, Guilford, v. 9, n. 5, p. 383-386, Oct. 1990.

TRINDADE, R. C. P.; MARQUES, I. M. R.; XAVIER, H. S.; OLIVEIRA, J. V. Extrato metanólico da amêndoa da semente de nim e a mortalidade de ovos e lagartas da traça-dotomateiro. Scientia Agricola, Piracicaba, v. 57, n. 3, p. 407413, jul./set. 2000.

VERKERK, R. H. J.; NEUGEBAUER, K. R.; ELLIS, P. R.; WRIGHT, D. J. Aphids on cabbage: tritrophic and selective insecticide interactions. Bulletin of Entomological Research, Wallingford, v. 88, p. 343-349, 1998.

WEBB, R.; HINEBAUGH, M. A.; RICHARD, K. L.; JACOBSON, M. Evaluation of aqueous solution of neem seed extract against Liriomyza sativae and L. trifolli (Diptera: Agromyzidae). Journal of Economic Entomology, College Park, v. 76, n. 2, p. 357-362, Apr. 1983. 